\title{
APLIKASI SISTEM PERHITUNGAN HARGA POKOK PRODUKSI ATAS PEMAKAIAN BAHAN BAKU MENGGUNAKAN METODE MOVING AVERAGE (STUDI KASUS : KEDAI PUTU)
}

\author{
Viona Firlisia, Marsani Asfi, Amroni \\ Sekolah Tinggi Manajemen Informatika dan Komputer CIC Cirebon \\ Jln. Kesambi 202, Kota Cirebon, Jawa Barat. Tlpn. (0231) 220250 \\ Email : vionafirlisia37@gmail.com, marsani.asfi@cic.ac.id, amroni@cic.ac.id
}

\begin{abstract}
Kedai Putu merupakan salah satu dari sekian banyak tempat kuliner yang tetap menjaga cita rasa dan kualitas pada makanan dan minuman yang dijual. Perkembangan bisnis kuliner yang sangat marak di kalangan semua lapisan masyarakat dapat dijadikan acuan untuk meningkatkan kualitas dari produk yang dijual. Bahan baku dalam pembuatan proses makanan dan minuman yang dijual harus mengutamakan cita rasa dari pelanggan yang sudah ada. Bahan baku merupakan hal utama untuk menjual produk makanan dan minuman yang dijual. Persediaan bahan baku seringkali menjadi tidak terkendali karena belum adanya sistem yang mengatur keluar dan masuknya bahan baku, sehingga menyebabkan harga yang dijual tidak sesuai dengan standar akuntansi dalam perhitungan persediaan bahan baku tersebut. Bahan baku yang tidak terpakai karena pada saat pembelian tidak memperhatikan jumlah yang tersedia maupun bahan baku yang dipakai terasa kurang karena pada saat pemakaian tidak memperhitungkan jumlahnya.Oleh karena itu, dalam penelitian yang dipakai untuk menghitung harga pokok produksi atas pemakaian bahan baku menggunakan metode moving average atau rata - rata bergerak, dengan judul Aplikasi Sistem Perhitungan Harga Pokok Produksi Atas Pemakaian Bahan Baku Menggunakan Metode Moving Average. Metode ini metode yang terletak di antara kedua metode FIFO dan LIFO, metode moving average mengambil nilai harga dari suatu harga pokok produksi bahan baku dengan cara membagi saldo dengan jumlah.Dengan adanya aplikasi ini dapat mempermudah manajemen dalam menghitung persediaan bahan baku, guna meningkatkan keamanan bahan baku dalam pemakaian maupun pembelian secara lebih stabil dan efektif agar tidak terjadi nya kerugian ataupun kecurangan yang merugikan perusahaan.
\end{abstract}

Kata Kunci : Bahan Baku, Persediaan, Moving Average

\begin{abstract}
Abstrak
Kedai Putu is one of the many culinary places that keeps the taste and quality of food and drinks to sell. The development of a culinary business that is very prevalent among all levels of society can be used as a reference to improve the quality of products sold. Ingredients in making the process of food and drinks sold must prioritize the taste of existing customers. The ingredients are the main thing to sell food and beverage products sold. Inventory of raw materials often becomes out of control because there is no system that regulates the exit and entry of raw materials, so that the prices sold are not in accordance with accounting standards in calculating the inventory of raw materials. Raw materials that are not used because at the time of purchase do not pay attention to the amount available and the raw material used feels less because at the time of use does not take into account the amount.Therefore, in the research used to calculate the cost of production for the use of raw materials using the moving average method, the title of the Cost of Product Calculation System Application for the Use of Raw Materials Using the Moving Average Method. This method is a method that is located between the two FIFO and LIFO methods, the moving average method takes the price value of a cost of production of raw materials by dividing the balance by the amount. With this application can facilitate management in calculating raw material inventory, in order to improve the safety of raw materials in the use and purchase in a more stable and effective so that no loss or fraud occurs that harm the company.
\end{abstract}

Keywords: Raw Materials, Inventories, Moving Average. 


\section{PENDAHULUAN}

Perkembangan bisnis kuliner sangat berdampak pada kehidupan sehari hari baik sebagai penjual maupun sebagai pembeli. Bisnis kuliner saat ini menggunakan media sosial untuk promosi dan pemesanan secara online. Dalam online, pemesanan dilakukan dengan melihat katalog yang berisi gambar atau video tentang makanan dan minuman yang dijual. Tingkat penggunaan media sosial yang tinggi menjadikan pelaku bisnis kuliner tertarik untuk mengembangkan setiap makanan dan minuman yang dijual secara online, selain menambah varian makanan dan minuman media katalog online yang diperbaharui terlihat lebih menarik. Salah satu aspek yang menjadi perhatian dalam penjualan adalah mengenai ketersediaan bahan baku. Bahan baku menjadi satu hal yang harus diperhitungkan ketersediaannya saat terjadinya penjualan. Tidak hanya ketersediaan, penyimpanan dan pengaturan bahan baku saat akan dikeluarkan juga perlu diperhatikan.

Dalam sistem akuntansi persediaan, khususnya persediaan bahan baku selalu terkait dengan transaksi pembelian, retur penjualan, pemakaian barang gudang, pengembalian barang gudang serta penghitungan fisik (Mulyadi, Sistem Akuntansi, halaman 554, th 2006). Dari lima transaksi yang terjadi dalam sistem akuntansi persediaan, di Kedai Putu hanya terjadi transaksi pembelian, transaksi pemakaian barang, pengembalian barang gudang, serta perhitungan fisik. Saat ini Kedai Putu belum memiliki manajemen stock dengan baik karena masih menggunakan cara yang manual dalam menghitung dan melaporkan ketersediaan bahan baku setiap harinya. Ketersediaan bahan baku hanya dihitung berdasarkan selisih antara pengecekan yang dilakukan dengan dua orang yang berbeda.

Kedai Putu merupakan tempat makan yang menyediakan menu makanan dan minuman Western. Nama Kedai Putu diambil dari bahasa Cirebon yaitu Putu yang berarti adalah cucu. Kedai Putu berdiri sejak 1 Juli 2013 yang bermula dari food truck yang berlokasi di Tuparev. Seiring dengan perkembangan pada Februari 2015, Kedai Putu membuka tempat yang terletak di Jalan Garuda Raya No.12. Kedai Putu sekarang berlokasi di Jalan Pagongan Nomer 106. Kedai Putu memiliki konsep yang menarik dan unik dengan mengutamakan kualitas pelanggan dan juga cita rasa dari setiap masakan dan minuman yang khas.

Metode yang digunakan untuk mencari dan menghitung persediaan bahan baku yang digunakan adalah metode Average dengan metode pencatatan persediaan prepetual karena metode ini tepat untuk dapat menentukan dan mengecek persediaan bahan baku yang ada dengan menghitung rata - rata persediaan yang ada pada Kedai Putu dan dapat menghasilkan kartu gudang sebagai persediaan bahan masuk dan bahan keluar serta kartu persediaan bahan baku yang akan dijadikan acuan untuk menghitung harga pokok penjualan.

Berdasarkan latar belakang tersebut penulis akan mengangkat permasalahan mengenai persediaan bahan baku yang akan dengan metode pencatatan Moving Average yang selanjutnya akan disajikan dalam bentuk skripsi dengan judul "Aplikasi Sistem Perhitungan Harga Pokok Produksi Atas Pemakaian Bahan Baku Menggunakan Metode Moving Average"

\section{KAJIAN PUSTAKA}

Sistem adalah serangkaian komponen yang dikoordinasikan untuk mencapai serangkaian tujuan. (Krismiaji,Sistem Informasi Akuntansi, 2010:p1)

Menurut Krisimiaji dalam bukunya Sistem Informasi Akuntansi menjelaskan jenis - jenis sistem dikelompokkan menjadi empat kelompok sebagai berikut :

1. Sistem tertutup (closed systems), yaitu sistem yang secara total terisolasi dari lingkunganya.

2. Sistem relatif tertutup (closed system), yaitu sistem yang berinteraksi dengan lingkungannya secara terkendali.

3. Sistem terbuka (Open systems), yaitu sistem yang berinteraksi dengan lingkungan secara tidak terkendali.

4. Sistem Umpan Balik (Feedback control systems), yaitu sistem yang menggunakan sebagai output menjadi salah satu input untuk proses yang sama di masa berikutnya. ( Krismiaji,2010,p:5) 


\subsection{HARGA POKOK PRODUKSI}

Menurut Bastian Bustami, dalam buku nya Akuntansi Persediaan,2010;p49, harga pokok produksi adalah kumpulan biaya produksi dalam proses awal dan dikurangi persedian produk dalam proses akhir. Harga pokok produksi terikat pada periode waktu tertentu. Harga pokok produksi akan sama dengan biaya produksi apabila tidak ada persediaan produk dalam proses awal dan akhir". Dalam definisi ini Bastian Bustami dan Nurlela menjelaskan bahwa harga pokok produksi berbeda dengan biaya produksi. Namun jika persediaan awal dan persediaan akhirnya tidak ada maka kedua unsur biaya ini adalah sama.

\subsection{METODE RATA - RATA BERGERAK}

Menurut Zaki Baridwan dalam bukunya Intermediate Accounting tahun 2014, dalam metode rata-rata bergerak barang-barang yang dipakai untuk diproduksi atau dijual akan dibebani harga pokok ratarata. Perhitungan harga pokok rata-rata dilakukan dengan cara membagi jumlah harga perolehan dengan kuantitasnya.

\subsection{METODE PREPETUAL}

Menurut Al. Haryono Jusup dalam bukunya Dasar - Dasar Akuntansi tahun 2011, dalam sistem persediaan perpetual, perusahaan menyelenggarakan pencatatan yang detil atas biaya perolehan persediaan barang dagangan yang dibeli maupun dijual. Pencatatan yang berlangsung terus menerus (perpetually) ini menujukan persediaan yang seharusnya ada untuk setiap jenis persediaan. Dengan kata lain, dengan sistem ini persediaan secara terus menerus dimutahirkan (updated).

\section{HASIL DAN PEMBAHASAN}

\section{A. Flowchart prosedur pembelian bahan baku}

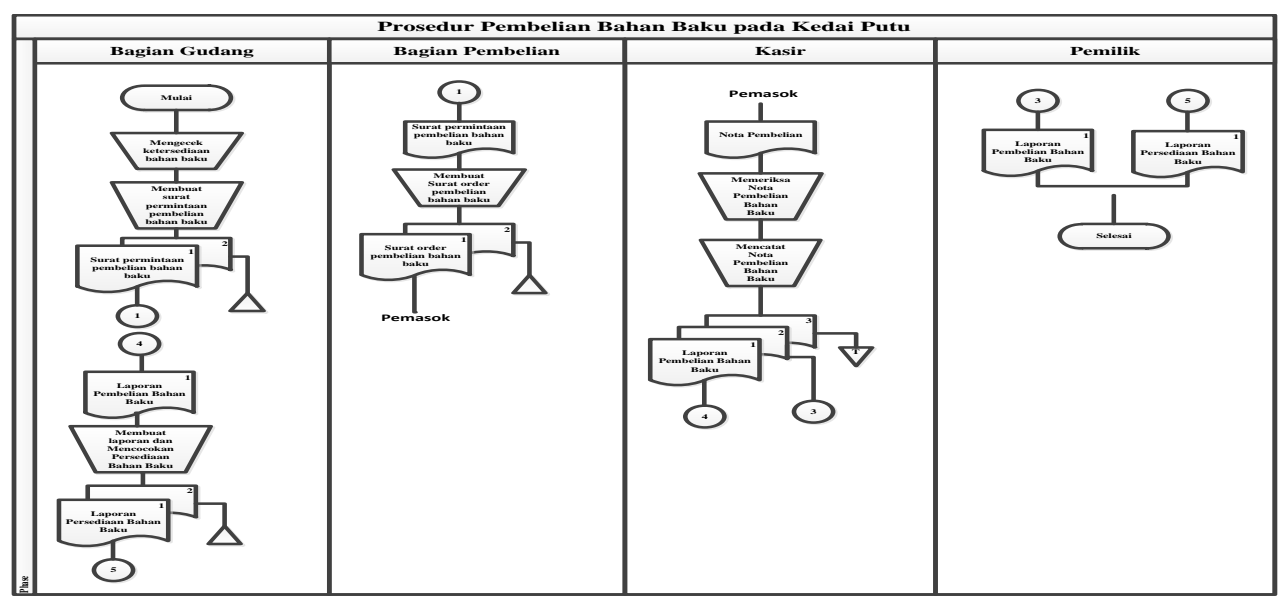

Gambar 3.2. Flowchart Prosedur Pembelian Bahan Baku 


\section{A. Flowchart Prosedur Pengeluaran Bahan Baku}

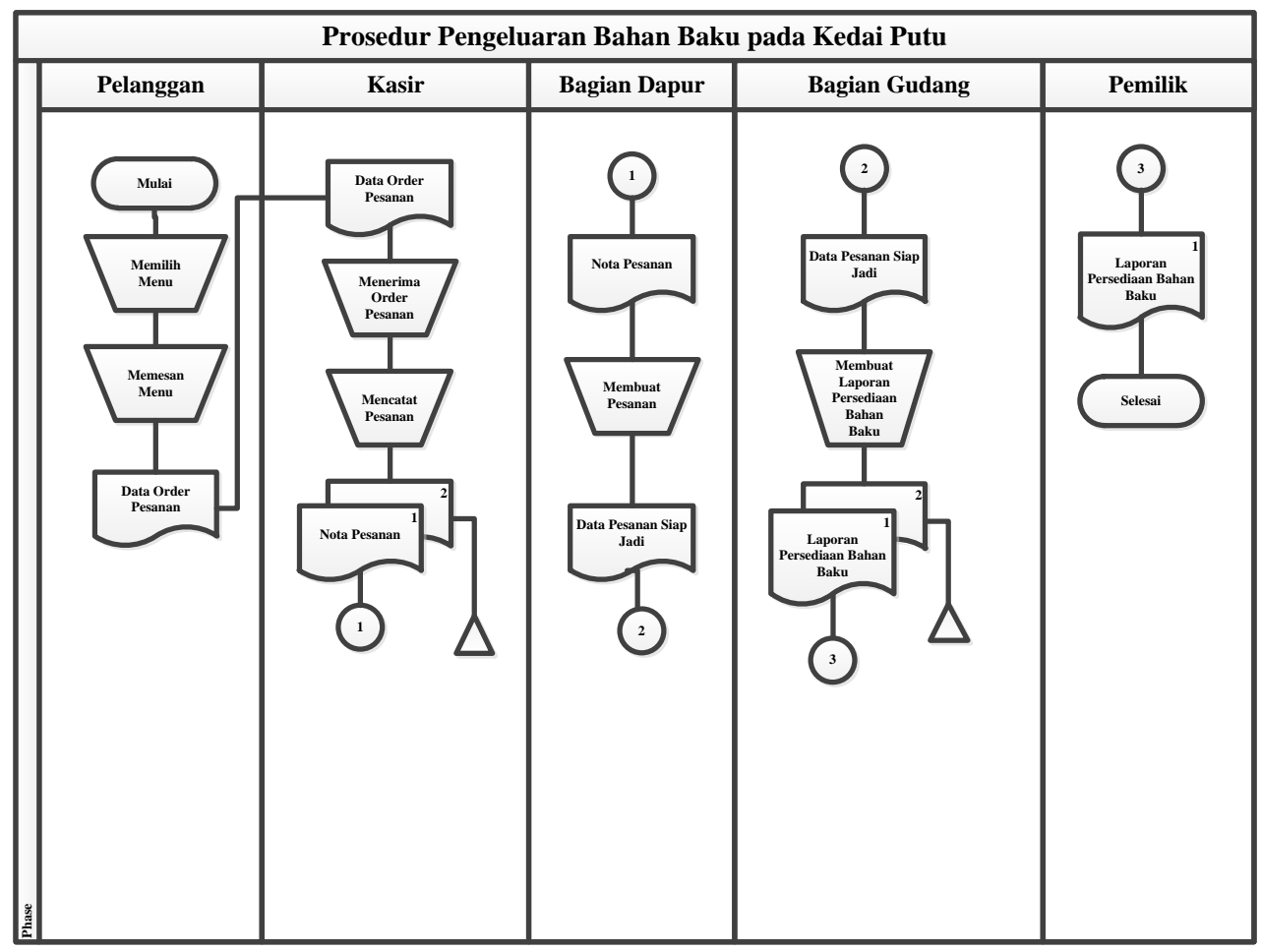

Gambar 3.3. Flowchart Prosedur Pengeluaran Bahan Baku

\subsection{FLOW MAP KOMPUTERISASI PERSEDIAAN BAHAN BAKU}

Berdasarkan hasil analisis penulis, dikarenakan pada Kedai Putu Cirebon belum memiliki catatan akuntansi dan masih terdapat penumpukan tugas pada satu bagian tertentu, yang dapat mengakibatkan hasil kinerja dan data yang dilaporkan menjadi tidak maksimal, maka penulis mengusulkan pembuatan tugas dan tanggung jawab dari masing - masing bagian yang terkait pada sistem persediaan yang akan diusulkan di Kedai Putu. Berikut merupakan tugas dari bagian yang diusulkan pada Aplikasi Sistem Perhitungan HPP Atas Pemakaian Bahan Baku Menggunakan Metode Moving Average di Kedai Putu Cirebon :

1. Bagian Pembelian membuat list pembelian bahan baku dan laporan pembelian.

2. Bagian Gudang membuat master bahan baku dan kartu gudang.

3. Bagian Produksi membuat daftar transaksi produksi

4. Bagian Kasir membuat kartu persediaan, jurnal pembelian, jurnal penjualan,jurnal pemesanan, buku besar, dan menu kedai putu. 
JURNAL DIGIT Vol. 9, No.1 Mei 2019, pp.110 121

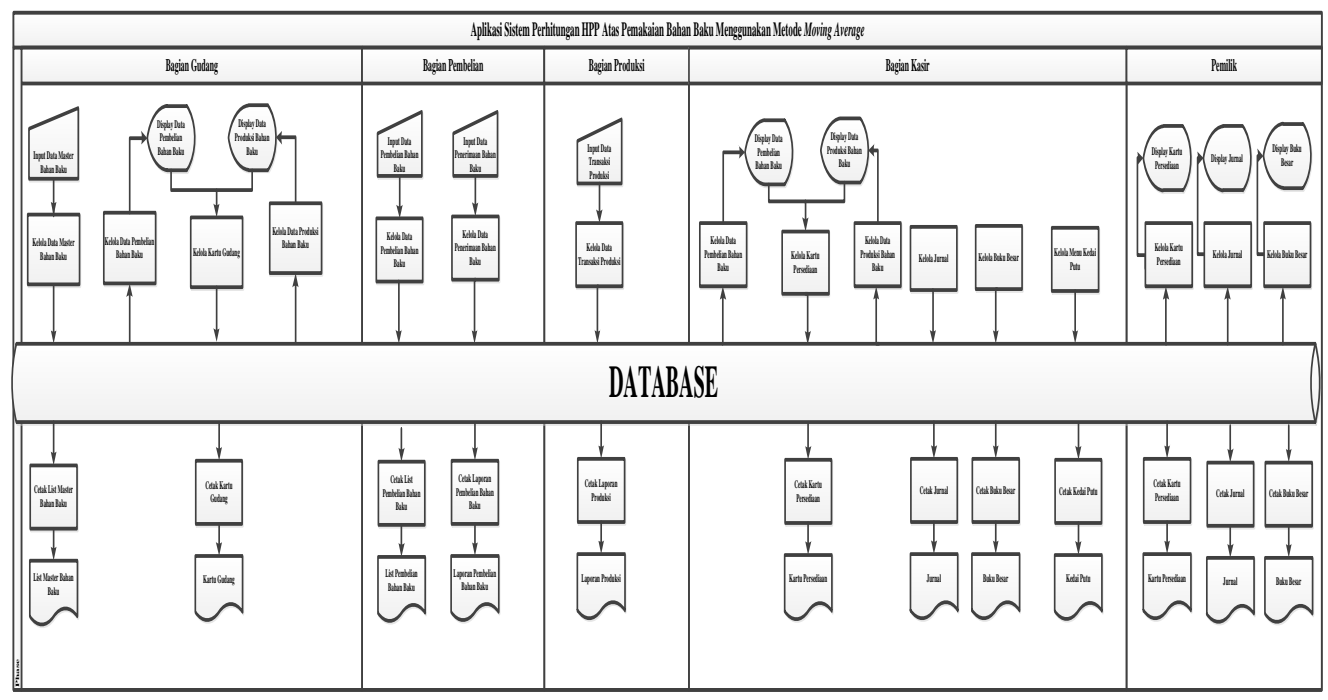

Gambar 3.1. Flow Map Komputerisasi Persediaan Bahan Baku

\subsection{DIAGRAM KONTEKS}

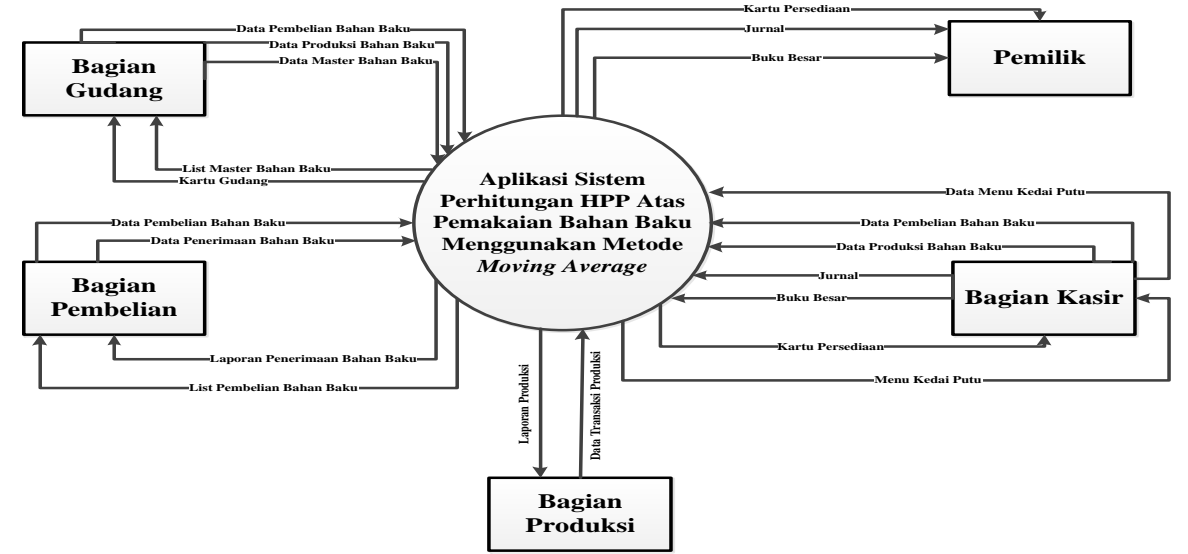

Gambar 3.2. Diagram Konteks Aplikasi Sistem Perhitungan Harga Pokok Produksi Atas Pemakaian Bahan Baku Menggunakan Metode Moving Avarage 


\subsection{DIAGRAM LEVEL 0}

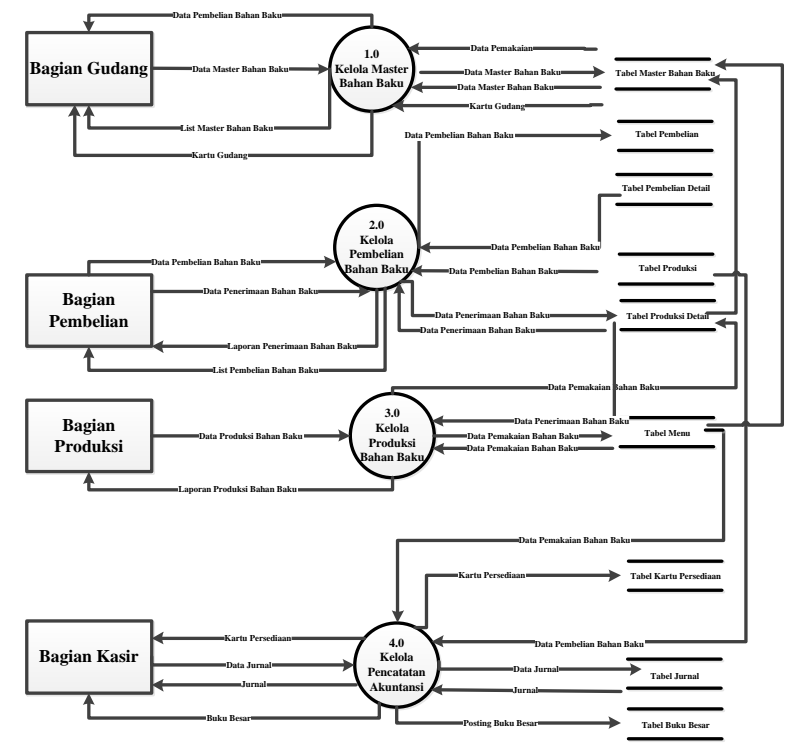

Gambar 3.3. Diagram Level 0 Aplikasi Sistem Perhitungan Harga Pokok Produksi Atas Pemakaian Bahan Baku Menggunakan Metode Moving Avarage

\section{IMPLEMENTASI SISTEM}

\subsection{IMPLEMENTASI RANCANGAN INPUT}

1. Form login

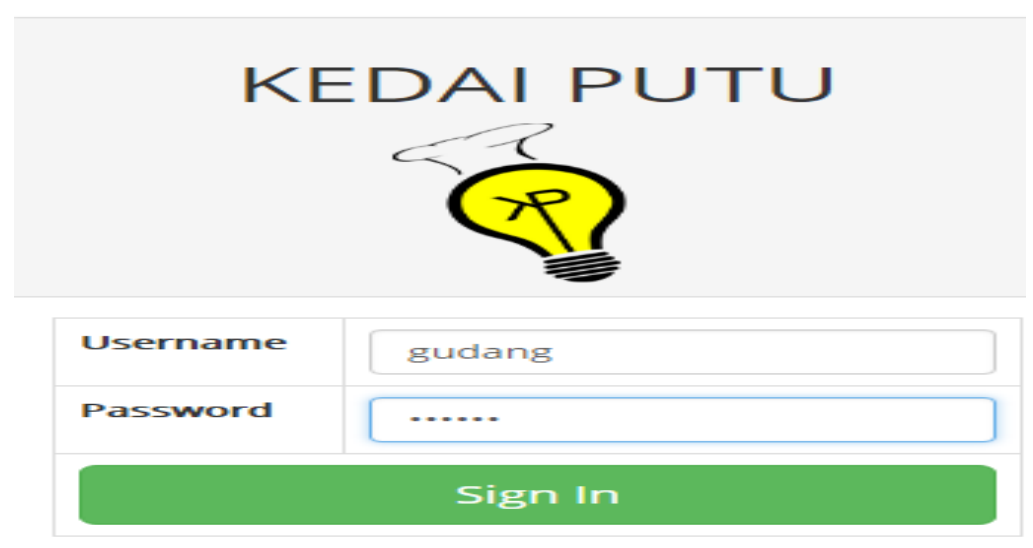

Gambar 3.4. Form Login

Aplikasi Sistem Perhitungan Harga Pokok Produksi Atas Pemakaian Bahan baku Menggunakan Metode Moving Average ( Studi Kasus : Kedai Putu )-(Viona Firlisia, Marsani, amroni) 
Form ini digunakan oleh user untuk mengakses aplikasi sesuai dengan tugas dan wewenang jabatannya, form login terlihat pada gambar 3.4. form ini terdiri dari username, password dan button sign in.

\section{2. . Form Menu Utama}

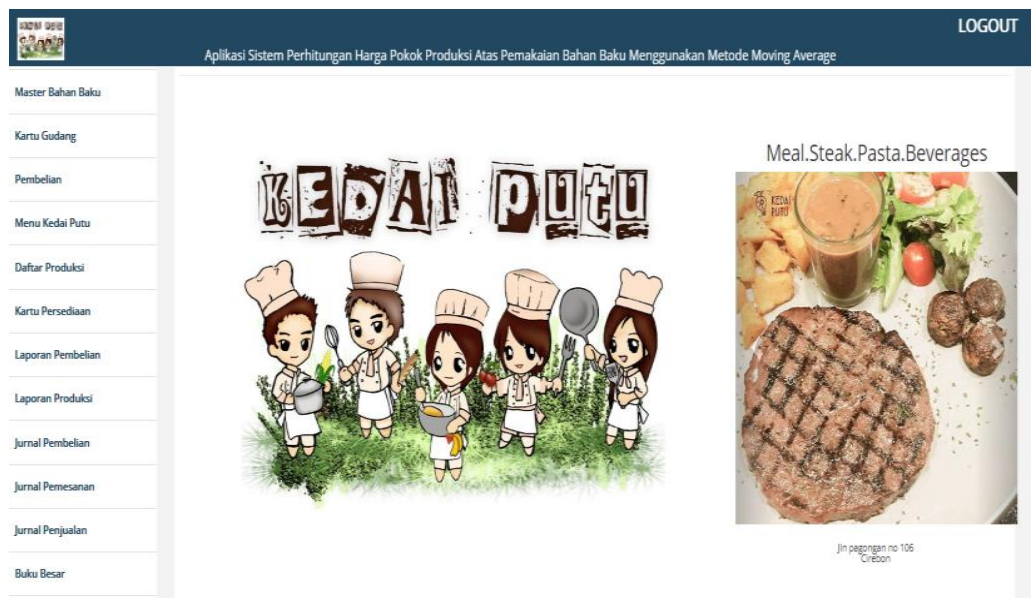

\section{Gambar 3.5. Form Menu Utama}

Form ini digunakan oleh user untuk melakukan kegiatan atau proses aktifitas yang terjadi pada Kedai Putu terlihat pada gambar 3.5.

\section{3. . Form Master Bahan Baku}

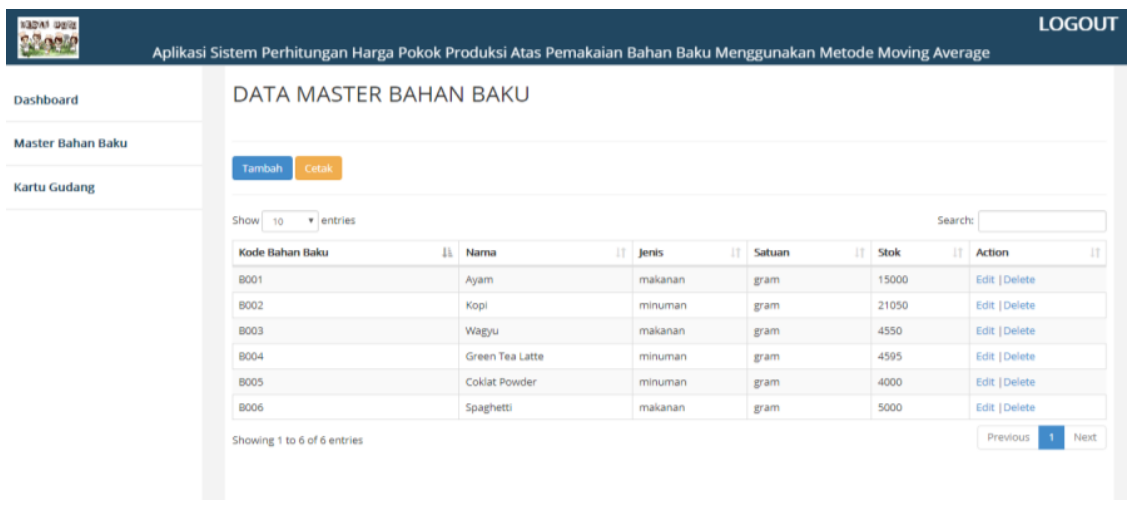

Gambar 3.6. Form Master Bahan Baku

Form ini digunakan oleh user untuk menambahkan data bahan baku yang dikelola oleh bagian gudang pada Kedai Putu terlihat pada gambar 3.6. 


\subsection{IMPLEMENTASI RANCANGAN OUTPUT}

OUTPUT PROSEDUR PENERIMAAN ORDER PELANGGAN

Berikut adalah beberapa output yang dihasilkan dari prosedur pembelian bahan baku dan produksi bahan baku yaitu :

\section{a. Kartu Gudang}

\begin{tabular}{|c|c|c|c|}
\hline 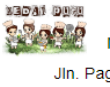 & \multicolumn{3}{|c|}{$\begin{array}{l}\text { KEDAI PUTU CIREBON } \\
\text { EAL, PASTA, STEAK, BEVERAGES } \\
\text { ggan No } 106 \text { Cirebon - Telp } 081220459637\end{array}$} \\
\hline \multicolumn{4}{|c|}{ KARTU GUDANG } \\
\hline Kode Barang & 8001 & Satuan & gram \\
\hline Nama Barang & Ayam & & \\
\hline Tanggal & Masuk & Keluar & Saldo \\
\hline $06-02-2019$ & 0 gram & 0 gram & 0 gram \\
\hline $07-02-2019$ & 10.000 gram & 0 gram & \begin{tabular}{|l|l|}
10.000 & $\mathrm{gram}$ \\
\end{tabular} \\
\hline $08-02-2019$ & 0 gram & 750 gram & 9.250 gram \\
\hline 09-02-2019 & 5.000 gram & 0 gram & $14.250 \mathrm{gram}$ \\
\hline $14-02-2019$ & o gram & 1.250 gram & $13.000 \mathrm{gram}$ \\
\hline 08-02-2019 & $2.000 \mathrm{gram}$ & o gram & $15.000 \mathrm{gram}$ \\
\hline
\end{tabular}

Cirebon, 08 February 2019

Administrator

Gambar 3.7. Kartu Gudang

b. Kartu Persediaan

\begin{tabular}{|c|c|}
\hline 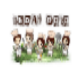 & 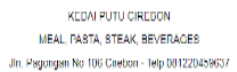 \\
\hline
\end{tabular}

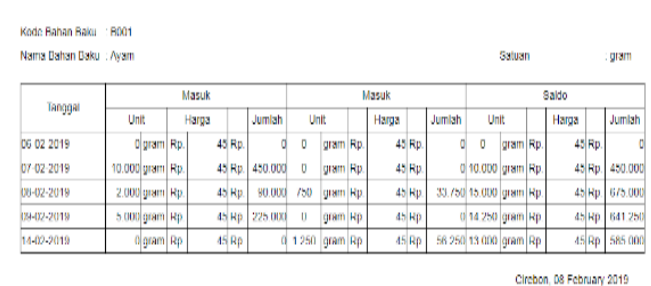

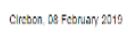

Administorter

Gambar 3.7. Kartu Persediaan

Aplikasi Sistem Perhitungan Harga Pokok Produksi Atas Pemakaian Bahan baku Menggunakan Metode Moving Average (Studi Kasus : Kedai Putu )-(Viona Firlisia, Marsani, amroni) 
c. Jurnal Pembelian

\begin{tabular}{|c|c|c|c|c|}
\hline \multirow[t]{2}{*}{ 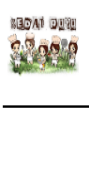 } & \multicolumn{4}{|c|}{$\begin{array}{c}\text { MEAL, PASTA, STEAK, BEVERAGES } \\
\text { JIn. Pagongan No } 106 \text { Cirebon - Telp } 081220459637\end{array}$} \\
\hline & \multicolumn{4}{|c|}{$\begin{array}{l}\text { JURNAL PEMBELIAN } \\
\text { Tanggal 01-02-2019 s/d 08-02-2019 }\end{array}$} \\
\hline Tanggal & Keterangan & & Debet & Kredit \\
\hline |07-02-2019 & $\begin{array}{l}\text { Persediaan Bahan Baku } \\
\text { Kas }\end{array}$ & Rp. & 450.000 & 450.000 \\
\hline 08-02-2019 & $\begin{array}{l}\text { Persediaan Bahan Baku } \\
\text { Kas }\end{array}$ & & 1.605 .500 & 1.605 .500 \\
\hline & Total & Rp. & $2.055 .500 \mathrm{R}$ & 2.055 .500 \\
\hline & & & Cirebon, 08 & sruary 2019 \\
\hline
\end{tabular}

Gambar 3.8. Jurnal Pembelian

d. Jurnal Pemesanan

\begin{tabular}{|c|c|}
\hline 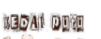 & KEDAI PUTU CIREBON \\
\hline 0.609 & MEAL, PASTA, STEAK, BEVERAGES \\
\hline & Jn. Pagongan NNo 106 Cirebon - Telp 081 \\
\hline
\end{tabular}

JURNAL PEMESANAN

01-02.2019 s/d 09.02-2019

\begin{tabular}{|c|c|c|c|c|c|c|}
\hline Tanggal & Nama Bahan Baku & Keterangan & & ebet & & Kredit \\
\hline 07-02-2019 & B001 - Ayam & $\begin{array}{l}\text { Barang Dalam Proses - Biaya Bahan Baku } \\
\text { Persediaan Produk Jadi }\end{array}$ & Rp. & $11.250,0$ & Rp. & $11.250,0$ \\
\hline $08-02-2019$ & B002 - Kopi & $\begin{array}{l}\text { Barang Dalam Proses - Biaya Bahan Baku } \\
\text { Persediaan Produk Jadi }\end{array}$ & Rp. & & Rp. & $5.250,0$ \\
\hline 09-02-2019 & B001 - Ayam & $\begin{array}{l}\text { Barang Dalam Proses - Biaya Bahan Baku } \\
\text { Persediaan Produk Jadi }\end{array}$ & RP. & $12.127,2$ & Rp. & $12.127,2$ \\
\hline \multicolumn{3}{|r|}{ Total } & Rp. & $28.627,2$ & Rp. & $28.627,2$ \\
\hline
\end{tabular}

Cirebon, 09 February 2019

Administrator 
e. Jurnal Penjualan

\begin{tabular}{|c|c|c|c|c|c|}
\hline \multirow[t]{2}{*}{ 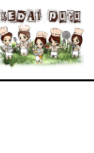 } & \multicolumn{3}{|c|}{$\begin{array}{c}\text { KEDAI PUTU CIREBON } \\
\text { MEAL, PASTA, STEAK, BEVERAGES } \\
\text { JIn. Pagongan No } 106 \text { Cirebon - Telp 081220459637 }\end{array}$} & & \\
\hline & \multicolumn{3}{|c|}{$\begin{array}{l}\text { JURNAL PENJUALAN } \\
\text { 01-02-2019 s/d 09-02-2019 }\end{array}$} & & \\
\hline Tanggal & Nama Bahan Baku & Keterangan & & Sebet & Kredit \\
\hline 07-02-2019 & B001 - Ayam & $\begin{array}{l}\text { Persediaan Produk Jadi } \\
\text { Barang Dalam Proses - Biaya Bahan Baku }\end{array}$ & Rp. & $11.250,\left.0\right|^{k}$ & $11.250,0$ \\
\hline 08-02-2019 & B002 - Kopi & $\begin{array}{l}\text { Persediaan Produk Jadi } \\
\text { Barang Dalam Proses - Biaya Bahan Baku }\end{array}$ & Rp. & $5.250,\left.0\right|^{R}$ & $5.250,0$ \\
\hline 09-02-2019 & B001 - Ayam & $\begin{array}{l}\text { Persediaan Produk Jadi } \\
\text { Barang Dalam Proses - Biaya Bahan Eaku }\end{array}$ & Rp. & $12.127,2 R_{R}$ & $12.127,2$ \\
\hline & & Total & Rp. & $28.627,2 \mid R$ & $28.627,2$ \\
\hline
\end{tabular}

Gambar 3.10. Jurnal Penjualan

\section{f. Buku Besar}

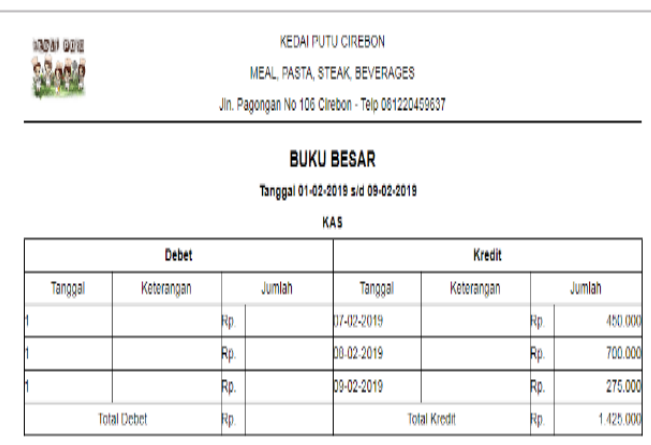

\begin{tabular}{|c|c|c|c|c|c|c|c|}
\hline \multicolumn{8}{|c|}{ PERSEDIAAN BAHAN BAKU } \\
\hline \multicolumn{4}{|c|}{ Dobot } & \multicolumn{4}{|c|}{ Krodt } \\
\hline \multirow{2}{*}{\begin{tabular}{|c|} 
Tannggal \\
$77 \cdot 022019$ \\
\end{tabular}} & \multirow[t]{2}{*}{ Kétermangan } & \multicolumn{2}{|c|}{ Jumlan } & \multirow[t]{2}{*}{ Tanggal } & \multirow[t]{2}{*}{ Keterangan } & \multicolumn{2}{|r|}{ Jumlan } \\
\hline & & RP. & 11250,0 & & & RP. & \\
\hline 88-12:2019 & & Rp & 82500 & & & Rp & \\
\hline 99022019 & & Rp. & 12.127 .2 & & & Rp. & \\
\hline \multicolumn{2}{|c|}{ Total Dobet } & RP. & 28627,2 & & & RP. & \\
\hline
\end{tabular}

Gambar 3.11. Buku Besar

\section{KESIMPULAN}

Berdasarkan hasil uraian dari bab I hingga bab V dan hasil observasi yang telah melalui tahap - tahap pengembangan perangkat lunak Aplikasi Sistem Perhitungan Harga Pokok Produksi Menggunakan Metode Moving Average maka penyusun memberikan kesimpulan sebagai berikut :

1. Aplikasi ini dapat membantu manajemen dalam menghitung bahan baku yang dibeli dan yang terpakai secara efesien dan mudah dengan menggunakan standar perhitungan akuntansi yaitu Moving Average. 
2. Aplikasi ini dapat menghitung secara langsung harga pokok produksi dari setiap menu makanan dan minuman yang dijual.

3. Dengan Aplikasi Sistem Perhitungan Harga Pokok Produksi Atas Pemakaian Bahan Baku Menggunakan Metode Moving Average dapat menjadi lebih cepat, lebih mudah dan data yang ada dapat tersimpan di database dengan rapih.

Berikut adalah prosedur - prosedur yang digunakan :

a. Prosedur pencatatan master bahan baku

b. Prosedur pencatatan transaksi pembelian bahan baku

c. Prosedur pencatatan transaksi produksi bahan baku

d. Prosedur pencatatan kartu gudang

e. Prosedur pencatatan kartu persediaan

f. Prosedur pencatatan jurnal dan buku besar

g. Prosedur penentuan harga pokok produksi menu makanan dan minuman

\section{SARAN}

Berdasarkan hasil observasi, perancangan dan pembuatan Aplikasi Sistem Perhitungan Harga Pokok Produksi Atas Pemakaian Bahan Baku Menggunakan Metode Moving Average pada Kedai Putu Cirebon. Beberapa usulan untuk pengembangan sistem komputerisasi kedepan, antara lain :

1. Penyajian data dalam sistem ini belum berupa grafik. Untuk itu perlu di kembangkan lagi penyajian data yang lebih beragam, untuk dapat melihat secara berkala dari data persediaan bahan baku agar dijadikan tolak ukur dalam pembelian atau pemakaian bahan baku di Kedai Putu Cirebon.

2. Perlu pengembangan dalam pembuatan laporan akuntansi sehingga memudahkan manajemen dalam menentukan harga pokok produksi

3. Perlu adanya metode pembanding dalam melakukan perhitungan harga pokok produksi beserta dengan persediaan bahan baku agar dapat mengetahui pemakaian dan pembelian dari masing - masing tiap jenis bahan baku yang ada di Kedai Putu Cirebon.

4. Pada aplikasi ini masih kurang dari sempurna, karena dalam perhitungan untuk menentukan harga pokok produksi tidak didukung dalam komponen utama biaya bahan baku, biaya tenaga kerja dan biaya overhead pabrik. Hanya memakai komponen yaitu biaya bahan baku. Jika dihitung tiga tiga nya akan dapat menghitung harga pokok produksi lebih jelas. Nilai harga pokok penjualan nya lebih cepat.

\section{Daftar Pustaka}

[1] Ahamad, Rizky, Sistem Informasi Akuntansi (Berbasis Akuntansi), Yogyakarta : CV Budi Utama, 2017.

[2] Al Fatta, Hanif, Analisis dan Perancangan Sistem Informasi, Yogyakarta : STMIK AMIKOM, 2007.

[3] Baridwan, Zaki, Intermediate Accounting, Edisi delapan, Yogyakarta : BPFE, 2014.

[4] Bastian,Bustami, Pengantar Akuntansi, Jakarta : Salemba Empat,2010.

[5] Fathansyah, Basis Data, Bandung : Informatika, 2004.

[6] Fathansyah, Ir, Basis Data, Bandung : Informatika, 2001.

[7]Indra, Dolly, Perancangan Sistem Informasi-II, Yogyakarta : Penerbit Unit dan Percetakan AMP YPKN, 2004.

[8]Jogiyanto, Hm, Analisis dan Desain Sistem Informasi : pendekatan terstruktur teori dan praktek aplikasi bisnis, Edisi Kedua, Yogyakarta : Andi, 2001.

[9]Jusup, Al Haryono, Dasar-dasar Akuntansi, Edisi tujuh, Yogyakarta : Sekolah Tinggi Ilmu Ekonomi YKPN, 2011.

[10]Krismiaji, Sistem Informasi Akuntansi, Edisi tiga, Yogyakarta : Sekolah Tinggi Ilmu Ekonomi YKPN, 2010.

[11] Mulyadi, Sistem Akuntansi, Edisi Keempat, Jakarta : Salemba Empat, 2016. 
[12[ Saputra, Agus, Panduan Praktis Menguasai Database Server MySQL, Jakarta : PT. Elex Media Komputido, 2011

[13] Sasongko, Catur, Akuntansi Suatu Pengantar-Berbasis PSAK Buku 1, Jakarta : Salemba Empat, 2016.

[14] Sidik, Ir. Betha, MySQL, Bandung : Informatika Bandung, 2003.

[15]Suprianto, Dodit, Dasar Pemrograman PHP, Bandung : OASE Media, 2008.

[16]Surjarweni,V. Wiratna, Pengantar Akuntansi, Yogyakarta : Pustaka Baru Press, 2016.

[17]Surjaweni, V.Wiratna, Sistem Akuntansi, Yogyakarta : Pustaka Barus Press, 2015.

[18]Yayah Pudin Shatu, Kuasai Detail Akuntansi Laba dan Rugi, Jakarta : Pustaka Ilmu Semesta, 2016. 